\title{
Knowledge level of physicians prescribing bisphosphonates: prevention and treatment of bisphosphonate-related osteonecrosis of the jaw
}

\author{
tahereh padeghaneh $^{1}$, nima dehghani ${ }^{1}$, and xaniar mahmoudi ${ }^{1}$ \\ ${ }^{1}$ Affiliation not available
}

July 21, 2020

\begin{abstract}
Rationale, aims and objectives: Bisphosphonate-related osteonecrosis of the jaw (BRONJ) is an important uncommon complication. Due to its complexity, its prevention requires a multidisciplinary approach, involving physicians and dental clinicians. This study aimed to assess the knowledge level of physicians prescribing bisphosphonates in Tehran about dental considerations in such patients and prevention and treatment of BRONJ in 2019. Methods: This descriptive, cross-sectional study evaluated 100 physicians (rheumatologists, endocrinologists, oncologists, and orthopedists) practicing in Tehran. A questionnaire comprising of a demographic section, and knowledge questions regarding dental considerations in patients taking bisphosphonates was administered among the physicians. The frequency of qualitative variables such as gender, type of specialty, and physicians' responses to each question was calculated, and the knowledge scores were analyzed separately based on the type of specialty of physicians using one-way ANOVA followed by the Tukey's test for pairwise comparisons. The effect of different variables on knowledge score was analyzed by simple regression. Results: The mean knowledge score of physicians was $5.19 \pm 1.78$ (range $2-8)$. The mean knowledge score of oncologists was significantly higher than that of endocrinologists $(5.88$ versus $4.52, \mathrm{P}=0.03)$. No other significant differences were noted. Work experience $(\mathrm{P}=0.04)$, age $(\mathrm{P}=0.02)$, orthopedics specialty $(\mathrm{P}=0.05)$ and oncology specialty $(\mathrm{P}=0.006)$ had significant effects on the knowledge score. Type of practice $(\mathrm{P}=0.75)$, gender $(\mathrm{P}=0.32)$, and rheumatology specialty $(\mathrm{P}=0.07)$ had no significant effect on the knowledge score. Conclusion: Considering acquiring about $50 \%$ of the total score, physicians seem to have limited knowledge about dental considerations in patients taking bisphosphonates. Attempts must be made to enhance their knowledge by the continuing education programs or revising the curricula.
\end{abstract}

\section{Keywords}

Knowledge, Tehran, bisphosphonates, Bisphosphonate-Related Osteonecrosis of the Jaw.

\section{1 | INTRIDUCTION}

Bisphosphonates are a group of medications prescribed for conditions such as osteoporosis and malignant bone metastasis. Bisphosphonates caused a great progress in treatment of musculoskeletal disorders such that they are currently among the most commonly used medications for clinical treatment of osteoporosis. Moreover, some reports are available regarding their effective role in management of some other skeletal and joint diseases such as the Paget's disease, bone metastasis, developmental anomalies, dysplastic fibrosis, Charcot arthropathy, sympathetic dystrophy, aseptic osteomyelitis, multiple myeloma, osteopenia, and osteogenesis imperfecta. ${ }^{1,2}$

Despite the numerous advantages of bisphosphonates, recently, osteonecrosis of the jaw was proposed as a major complication developing in patients taking bisphosphonates. Bisphosphonate-related osteonecrosis of the jaw (BRONJ) was first described by Marx in 2003; since then, number of reported cases of BRONJ has increased. ${ }^{3-6}$ The exact mechanism of BRONJ has not yet been clarified. BRONJ is characterized by an 
exposed area of jawbone, remaining for more than 8 weeks in patients who have not undergone radiotherapy but have a history of, or are currently taking bisphosphonates. ${ }^{7}$ Bisphosphonates are deposited in bone and are integrated into the bone matrix. During the bone remodeling process, bisphosphonates are taken up by osteoclasts. In their cytoplasm, bisphosphonates inhibit the activity of osteoclasts and induce their apoptosis. Bisphosphonates inhibit the osteoclastic bone resorption, with the help of osteoblasts. They also have anti-angiogenic properties. Under such circumstances, the bone turnover greatly decreases, and the bone undergoes slight physiological remodeling over time. Thus, the bone becomes brittle and cannot repair the tiny fractures that occur during daily activities.

This study aimed to assess the knowledge level of physicians prescribing bisphosphonates (oncologists, orthopedists, rheumatologists, and endocrinologists) in Tehran city about dental considerations in such patients and prevention and treatment of BRONJ in 2019.

\section{2 | METHODOLOGY}

This descriptive, cross-sectional study evaluated four groups of physicians namely oncologists, orthopedists, rheumatologists, and endocrinologists practicing in private and public sectors in Tehran city. The list of names of all specialists practicing in Tehran in 2019 was obtained from the Medical Council of Iran. After obtaining their address and necessary coordination, they were provided with a questionnaire and a return envelope. An arrangement was then made with their secretary for collection of the completed questionnaires. The physicians were ensured about the confidentiality of their information, and the questionnaires were filled out anonymously.

The inclusion criteria were being a member of the Medical Council of Iran, having permanent work permit, and clinical practice in private or public sector in Tehran city. Physicians without clinical practice and those unwilling to participate in the study were excluded.

A researcher-designed questionnaire was used to assess the knowledge level of physicians about BRONJ, and its prevention and treatment. The first part of the questionnaire asked for the demographic information of participants such as their age, gender, and work experience (in years). The second part of the questionnaire contained questions to assess the knowledge level of participants regarding dental considerations in patients taking bisphosphonates, and prevention and treatment of BRONJ. In order to assess the content validity of the questions, three faculty members were requested to read the questionnaire and apply the necessary modifications. Inappropriate questions were deleted according to their expert opinion, and necessary modifications were made. In case of no response to over $25 \%$ of the questions, the respective questionnaire would be excluded from the final analysis. After completion of 20 questionnaires by the physicians, the reliability of the questions was evaluated using the Cronbach's alpha. The Cronbach's alpha coefficient can range from 1 to 0 , and indicates the internal consistency of the questions. Cronbach's alpha $=0$ indicates absence of internal consistency and reliability while Cronbach's alpha $=1$ indicates complete internal consistency or reliability. The reliability of the questionnaire after two assessments was calculated to be 0.75 , which was acceptable.

\section{3 | RESULTS}

A total of 100 physicians practicing in Tehran participated in this study including 25 orthopedists, 25 oncologists, 25 rheumatologists and 25 endocrinologists. There were 36 females and 63 males in the study; the gender of one participant was not specified. Table 1 summarizes the responses of physicians. Each correct answer was given a score of 1 while each incorrect answer was allocated a 0 score. Accordingly, the mean knowledge score of physicians was found to be $5.19 \pm 1.78$ (range 2-8).

Table 2 shows the frequency of each score acquired by the physicians. According to one-way ANOVA, a significant difference existed in the knowledge score of different specialty groups $(\mathrm{P}=0.05)$. Thus, pairwise comparisons were carried out using the Tukey's test, which revealed a significant difference between endocrinologists and oncologists regarding their knowledge level about dental considerations in patients taking bisphosphonates $(\mathrm{P}=0.03)$. However, the difference between orthopedists and rheumatologists $(\mathrm{P}=0.88)$, orthopedists and endocrinologists $(\mathrm{P}=0.33)$, oncologists and rheumatologists $(\mathrm{P}=0.29)$, and rheumatologists 
and endocrinologists $(\mathrm{P}=0.76)$ was not significant. Table 3 shows the measures of central dispersion of the knowledge score of different specialty groups.

According to the results of the regression test (Table 4), parameters such as the work experience $(\mathrm{P}=0.04)$, age $(\mathrm{P}=0.02)$, orthopedics specialty $(\mathrm{P}=0.04)$ and oncology specialty $(\mathrm{P}=0.006)$ had significant effects on the knowledge score. However, the type of practice (private or public sector) $(\mathrm{P}=0.75)$, gender $(\mathrm{P}=0.32)$, and rheumatology specialty $(\mathrm{P}=0.07)$ had no significant effect on the knowledge score.

\section{4 | DISCUSSION}

Since the first report regarding BRONJ in 2003, several clinical and experimental studies have been conducted regarding its diagnosis, treatment and prognosis; however, many aspects related to this condition are still unclear. ${ }^{8}$ Due to the risk of recurrence of osteonecrosis of the jaw, there is no doubt that prevention is the best method of treatment. Thus, physicians should refer the patients for dental assessments and determination of risk factors prior to administration of bisphosphonates for them. ${ }^{9-11}$

In 2005, the Food and Drug Administration pointed to the risk of BRONJ to raise awareness about this condition among the health professionals. Kim et al, in 2016 reported that $9.21 \%$ of medical professionals had not heard about BRONJ while $9.9 \%$ correctly answered all five questions about it, indicating the poor knowledge of medical professionals about BRONJ. ${ }^{7}$

Treatment of periodontal disease and oral and dental care are highly important in patients requiring bisphosphonate therapy. ${ }^{11,12}$ Thus, they need to be informed about the incidence and significance of BRONJ and should be provided with the necessary instructions in this respect.

The incidence of BRONJ following intravenous injection of bisphosphonates is $0.8 \%$ to $1.2 \%{ }^{13}$ This rate is $0.00038 \%$ to $0.06 \%$ in patients with oral intake of bisphosphonates. ${ }^{14}$ The diagnosis of BRONJ is not easy, and a diagnosis may not be reached due to conditions related to oral surgery. ${ }^{15}$ Thus, correct diagnosis of BRONJ is imperative in patients taking bisphosphonates. Mucosal ulceration and suppurative infection exposing the underlying bone is the most common clinical presentation of BRONJ. On the other hand, BRONJ does not well respond to different treatments. Thus, its prevention, and early and accurate diagnosis are highly important. ${ }^{13}$ Osteonecrosis of the jaw often develops in patients with intravenous administration of bisphosphonates; however, patients with oral intake of bisphosphonates may also develop BRONJ in some cases. Risk of development of osteonecrosis is low in patients using oral bisphosphonates for less than 3 years; therefore, this time period is ideal for assessment of oral and dental status of patients. ${ }^{16,17}$

Review of the literature on this topic revealed that most available studies have been conducted on the knowledge level of dental clinicians about BRONJ, and information regarding the knowledge level of physicians on this topic is limited. Hristamyan-Cilev et al, in 2019 evaluated the knowledge level of dentists practicing in Plovdiv, Bulgaria and reported that $17.03 \%$ of the participants had no knowledge about bisphosphonates and their side effects. Half of them reported that they had not visited any patient with complications of bisphosphonate treatment in their office, which could be related to their lack of knowledge in this respect. ${ }^{18}$ Kim et al. assessed the knowledge level of internal medicine specialists, family physicians, and orthopedists practicing in six medical centers in Seoul, and found that less than $30 \%$ of the patients had been referred to dental clinicians by physicians. Oncologists better detected the need for referral of patients to dental clinicians, followed by endocrinologists, rheumatologists, family physicians, and orthopedists. ${ }^{7}$ Senturk et al, in 2016 evaluated the knowledge level of oncologists in Ankara city about the adverse side effects and positive effects of bisphosphonates; $66 \%$ of them reported that BRONJ was the most common complication of taking bisphosphonates, and $39.6 \%$ reported referral of patients to dental clinicians, which was almost similar to the rate in our study. ${ }^{19} \mathrm{Al}-$ Mohaya et al. found that the knowledge level had a significant correlation with expertise, work experience (years), and having a specialty degree. ${ }^{20}$ It seems that aging and gaining work experience improve the knowledge of physicians about different diseases and their prevention and treatment. Since male and female physicians receive the same instructions in medical schools, the insignificant effect of gender on knowledge level is expected. On the other hand, younger graduates still have a fresh memory of what they have been taught in the university; this may explain the difference in the knowledge level of 
physicians with variable work experiences. When the physicians do not encounter such patients, they may forget the management of such cases over time unless they receive complementary education in this respect.

According to the suggested mechanism, bisphosphonates decrease the bone turnover, prevent the activity of osteoclasts, decrease bone remodeling, and exert their therapeutic effects as such. ${ }^{21}$ Thus, decreasing bone resorption and increasing the bone density can prevent angiogenesis and lead to necrosis of bone cells. ${ }^{22}$ Since BRONJ is a possible side effect of bisphosphonate intake, physicians and other health professionals should be aware of the mechanism of action of bisphosphonates.

Dentoalveolar surgery is the main risk factor for BRONJ. Moreover, periodontal disease, denture use, and implant placement can serve as predisposing factors for BRONJ. ${ }^{9}{ }^{23}$ In addition to local factors, parameters such as the type of bisphosphonate, duration of treatment, and form of prescribed medication can affect the development of BRONJ. Also, bisphosphonates containing nitrogen that are administered intravenously for a long period of time are a major risk factor for development of BRONJ. ${ }^{9}$

In patients at high risk of BRONJ, dental procedures such as tooth extraction, endodontic surgery, and implant placement should be preferably avoided. ${ }^{24}$ Some dental procedures such as tooth extraction are a major risk factor for BRONJ. Evidence shows that tooth extraction is a common cause of BRONJ, causing this condition in $52 \%$ to $61 \%$ of the cases. ${ }^{9,}{ }^{25-27}$ A cohort study reported that patients receiving bisphosphonate IV (zoledronate) who were candidates for dentoalveolar surgery (tooth extraction) had 33 times higher risk of development of BRONJ compared with those who were not candidates for this type of surgery. Some specialists discontinue the medication until its side effects vanish; this was particularly emphasized by Senturk et al. ${ }^{19}$ Temporary discontinuation of medication (drug holiday) has been beneficial for prevention of BRONJ in some cases, and seems to be the first treatment strategy for BRONJ. ${ }^{28,}{ }^{29}$ Nonetheless, temporary discontinuation of drug seems to have no short-term benefit, but long-term discontinuation can help reach stability in areas of BRONJ, and decrease its signs and symptoms. However, risk of metastasis and aggravation of bone disorders increases in cancer patients upon discontinuation of bisphosphonates. ${ }^{30-32}$

As mentioned earlier, prevention is the best option for treatment of BRONJ. Accordingly, the risk of development of BRONJ decreases in case of referral of such patients by physicians to dentists. It is suggested to assess the oral health status of patients prior to the initiation of treatment with bisphosphonates and enhance the knowledge of patients regarding the risk of BRONJ. ${ }^{29}$ Also, the patients should be provided with necessary oral hygiene instructions and should be informed about the signs and symptoms of BRONJ. ${ }^{30}$ Screening and routine dental examination should be repeated every 3 months for such patients because bisphosphonates have long-term effects on bone. ${ }^{23}$ Thus, dental clinicians should be involved in treatment of such patients.

\section{5 | CONCLUSION}

Enhanced knowledge of healthcare providers such as physicians and dentists about bisphosphonates can decrease the incidence of BRONJ and lead to a more favorable recovery. ${ }^{26}$ Also, improved instruction of patients regarding the use and side effects of bisphosphonates by physicians and dentists can promote the quality of care and decrease the side effects of medical and dental treatments. ${ }^{33}$ The current results showed that physicians practicing in Tehran had some knowledge about dental considerations in patients taking bisphosphonates; however, their lack of knowledge about some items was obvious.

Authorship:

TP was involved in the conception and design of the work, data collection, drafting of the manuscript, critical revision of the manuscript, and final approval of the version to be published.

ND was involved in the conception and design of the work, data collection, drafting of the manuscript, critical revision of the manuscript, and final approval of the version to be published.

$\mathrm{XM}$ was involved in the conception and design of the work, data collection, drafting of the manuscript, critical revision of the manuscript, and final approval of the version to be published.

ACNOWLEDGEMENTS: We wish to thank the physicians who took part in the study. 
Conflict of Interest: None declared

Funding Information: No sources of funding are declared for this study.

References

1- Chapurlat RD, Delmas PD, Liens D, Meunier PJ. Long-term effects of intravenous pamidronate in fibrous dysplasia of bone. J Bone Miner Res. 1997; 12(10):1746-1152.

2- Verenna M, Zucchi F, Ghiringhelli D, Binelli L, Bevilacqua M, Bettica P. Intravenous clodronate in the treatment of reflex sympathetic dystrophy syndrome. A randomized, double blind, placebo controlled study. J Rheumatol. 2000; 27(6):1477-1483.

3- Rosenberg TJ, Ruggiero S. Osteonecrosis of the jaws associated with the use of bisphosphnates. J Oral Maxillofac Surg. 2003; 61(8):60-61.

4- Ruggiero SL, Mehrotra B, Rosenberg TJ, Engroff SL. Osteonecrosis of the jaws associated with the use of bisphosphonates: a review of 63 cases. J Oral Maxillofac Surg. 2004; 62(5):527-534. 5- Greenberg MS. Intravenous bis-phosphonates and osteonecrosis. Oral Surg Oral Med Oral Radiol Endod. 2004; 93(3):259260. 6- Marx RE, Sawatari Y, Fortin M, Broumand V. Bisphosphonate-induced exposed bone (osteonecrosis osteopetrosis) of the jaws: risk factors, recognition, prevention and treatment, J Oral Maxillofac Surg. 2005; 63(11):1567-1575.

7- Kim JW, Jeong SR, Kim SJ, Kim Y. Perceptions of medical doctors on bisphosphonate-related osteonecrosis of the jaw. BMC Oral Health. 2016; 16(1):92.

8- Reid IR, Cornish J. Epidemiology and pathogenesis of osteonecrosis of the jaw. Nat Rev Rheumatol. 2012; 8:90-96.

9- Ruggiero SL, Dodson TB, Fantasia J, Goodday R, Aghaloo T, Mehrotra B, O'Ryan F. American Association of Oral and Maxillofacial Surgeons position paper on medication-related osteonecrosis of the jaw-2014 update. J Oral Maxillofac Surg. 2014; 72:1938-1956. 10- Khan AA, Morrison A, Hanley DA, Felsenberg D, McCauley LK, O'Ryan F, Reid IR, Ruggiero SL, Taguchi A, Tetradis S, Watt NB, Brandi ML, Peters E, Guise T, Eastell R, Cheung AM, Morin SN, Masri B, Cooper C, Morgan SL, Obermayer-Pietsch B, et al. Diagnosis and management of osteonecrosis of the jaw: a systematic review and international consensus. J Bone Miner Res. 2015; 30:3-23.

11- Lam DK, Sandor GK, Holmes HI, Evans AW, Clokie CM. A review of bisphosphonate-associated osteonecrosis of the jaws and its management. J Can Dent Assoc 2007; 73:417-422.

12- Khosla S, Burr D, Cauley J, Dempster DW, Ebeling PR, Felsenberg D, Gagel RF, Gilsanz V, Guise T, Koka S, et al. Bisphosphonate-associated osteonecrosis of the jaw: report of a task force of the American Society for Bone and Mineral Research. J Bone Miner Res 2007; 22:1479-1491.

13- Pazianas M, Miller P, Blumentals WA, Bernal M, Kothawala P. A review of the literature on osteonecrosis of the jaw in patients with osteoporosis treated with oral bisphosphonate: prevalence, risk factors, and clinical characteristics. Clin Ther 2009; 29:1548-1558.

14- Paeng JY. Diagnosis and management of BRONJ (bisphosphonate related osteonecrosis of jaw). J Korean Dent Assoc 2011; 49:378-388. 15- Choi SW, Kim SR, Lee KB. Osteonecrosis of the jaw in a patient with osteoporosis treated with oral bisphosphonates. J Korean Orthop Assoc 2010; 45:151-154.

16- Khan AA, Sandor GK, Dore E. Canadian consensus practice guidelines for bisphosphonate associated osteonecrosis of the jaw. J Rheumatol 2008; 35(7):1391-1397.

17- Epstein JB, Kish RV, Hallajian L, Sciubba J. Head and neck oral and orophryngeal cancer: a review of medicolegal cases. Oral Surg Oral Med Oral Pathol Oral Radiol 2015; 119:177-186. 
18- Hristamyan-Cilev MA, Pechalova PP, Raycheva RD, Hristamyan VP, Kevorkyan AK, Stoilova YD. Bisphosphonate-associated osteonecrosis of the jaws: a survey of the level of knowledge of dentists about the risks of bisphosphonate therapy. Folia Med (Plovdiv) 2019; 1; 61(2):303-311.

19- Senturk MF, Cimen E, Tuzuner Oncul AM, Cambazoglu M. Oncologist's awareness about bisphosphonate related osteonecrosis of the jaws. J Pak Med Assoc 2016; 66(7):880-883.

20- Al-Mohaya MA, Al-Khashan HI, Mishriky AM, Al-Otaibi LM. Physicians' awareness of bisphosphonatesrelated osteonecrosis of the jaw. Saudi Med J 2011; (8):830-835.

21- Bauer JS, Beck N, Kiefer J, Stockmann P, Wichmann M, Eitner S. Awareness and education of patients receiving bisphosphonates. J Craniomaxillofac Surg 2012; 40:277-282. 22- Wood J, Bonjean K, Ruetz S, Bellahcene A, Devy L, Foidart JM, Castronovo V, Green JR. Novel antiangiogenic effects of the bisphosphonate compound zolendronic acid. J Pharmacol Exp Ther 2002; 302:1055-106.

23- Ruggiero SL, Dodson TB, Assael LA, Landsberg R, Mars RE, Mehrotra B. American Association of oral and maxillofacial surgeons' positions paper on bisphosphonate-related osteonecrosis of the jaws-2009 update. J Oral Maxillofac Surg 2009; 67:2-12.

24- Moinzadeh AT, Shemesh H, Neirynck NA, Aubert C, Wesselink PR. Bisphosphonates and their clinical implications in endodontic therapy. Int Endod J 2013; 46(5):391-398.

25- Vahtsevanos K, Kyrgidis A, Verrou E, Katodritou E, Triaridis S, Andreadis CG, Boukovinas I, Koloutsos GE, Teleioudis Z, Kitikidou K, Paraskevopoulos P, Zervas K, Antoniadaes K. Longitudinal cohort study of risk factors in cancer patients of bisphosphonate-related osteonecrosis of the jaw. J Clin Oncol 2009; 27:53565362. 26- Saad F, Brown JE, Van Poznak C, Ibrahim T, Stemmer SM, Stopeck AT, Diel IJ, Takahashi S, Shore N, Henry DH, Barrios CH, Facon T, Senecal F, Fizazi K, Zhou L, Daniels A, Carriere P, Dansey R. Incidence, risk factors, and outcomes of osteonecrosis of the jaw: integrated analysis from three blinded active-controlled phase III trials in cancer patients with bonemetastases. Ann Oncol 2012; 23:1341-1347. 27Fehm T, Beck V, Banys M, Lipp HP, Hairass M, Reinert S, Solomayer EF, Wallwiener D, Krimmel M. Bisphosphonate-induced osteonecrosis of the jaw (ONJ): Incidence and risk factors in patients with breast cancer and gynecological malignancies. Gynecol Oncol 2009; 112:605-609.

28- Dickinson M, Prince HM, Kirsa S, Zannettino A, Gibbs SD, Mileshkin L, OGrady J, Seymour JF, Szer J, Horvath N, Joshua DE. Osteonecrosis of the jaw complicating bisphosphonate treatment for bone disease in multiple myeloma: an overview with recommendations for prevention and treatment. Intern Med J 2009; 39:304-316.

29- Kwon YD, KimYR, Choi BJ, Lee DW, Kim DY. Oral bis-phosphonate related osteonecrosis of the jaws: favorable outcome after bisphosphonate holiday. Quintessence Int 2009; 40:277-278.

30- .McLeod NM, Brennan PA, Ruggiero SL. Bisphosphonate osteonecrosis of the jaw: a historical and contemporary review. Surgeon 2012; 10:36-42. 31.Vescovi P, Merigo E, Meleti M, Manfredi M, Guidotti R, Nammour S. Bisphosphonates-related osteonecrosis of the jaws: a concise review of the literature and a report of a single-centre experience with 151 patients. J Oral Pathol Med 2012; 41:214-221. 32- Patel V, McLeod NM, Rogers SN, Brennan PA. Bisphosphonate osteonecrosis of the jaw-a literature review of UK policies versus international policies on bisphosphonates, risk factors and prevention. Br J Oral Maxillofac Surg 2011; 49:251-257.

33- Migliorati CA, Mattos K, Palazzolo MJ. How patients' lack of knowledge about oral bisphosphonates can interfere with medical and dental care. J Am Dent Assoc 2010; 141(5):562-566

\section{Hosted file}

Table 1.docx available at https://authorea.com/users/344733/articles/471146-knowledge-levelof-physicians-prescribing-bisphosphonates-prevention-and-treatment-of-bisphosphonaterelated-osteonecrosis-of-the-jaw 


\section{Hosted file}

Table 2.docx available at https://authorea.com/users/344733/articles/471146-knowledge-levelof-physicians-prescribing-bisphosphonates-prevention-and-treatment-of-bisphosphonaterelated-osteonecrosis-of-the-jaw

\section{Hosted file}

Table 3.docx available at https://authorea.com/users/344733/articles/471146-knowledge-levelof-physicians-prescribing-bisphosphonates-prevention-and-treatment-of-bisphosphonaterelated-osteonecrosis-of-the-jaw 